\title{
MATERNAL HLA-DR HOMOZYGOSITY IS NOT ASSOCIATED WITH AN INCREASED RISK OF FETAL LOSS
}

\author{
DAVID C. KILPATRICK* \\ Department of Transfusion Medicine, The Royal Infirmary, Edinburgh, Scotland.
}

\begin{abstract}
SUMMARY
An attractive but controversial hypothesis holds that HLA similarity between mother and offspring predisposes to early fetal loss. Against this background, Hoff et al. (1992) have reported a significant association between maternal HLA-DR homozygosity and fetal loss in a cohort of multigravid American women. To re-examine this finding independently. a similar investigation was carried out on a comparable group of British subjects. The HLA-DR data of 75 multigravid women were analysed: the proportion of women who had experienced fetal loss did not differ between HLA-DR homozygous and heterozygous subjects.
\end{abstract}

KEY WORDS HLA-DR homozygosity Fetal loss Spontaneous abortion

\section{INTRODUCTION}

A large and controversial literature exists concerning an alleged association between parental (and hence feto-maternal) HLA antigen sharing and fetal loss (Johnson and Ramsden, 1988; Eroglu et al., 1992). Although couples experiencing recurrent spontaneous abortion (RSA) may genuinely share more HLA antigens in general than normal couples, the relationship, if it exists, is weak, and several convincing studies have demonstrated that HLA sharing per se between mother and fetus does not predispose to spontaneous abortion (MacQueen and Sanfilippo, 1984; Morgan et al., 1986; Jazwinska et al.. 1987).

Neither feto-maternal HLA-DR sharing nor maternal HLA-DR homozygosity was associated with pregnancy wastage in a typical British population selected irrespective of previous fetal losses (Jazwinska et al., 1987), nor was parental HLA-DR sharing associated with fetal loss in an inbreeding American Hutterite population (Ober et al.,1992). However, Hoff et al. (1992) have recently reported a strong relationship between maternal HLA-DR homozygosity and fetal wastage in a random cohort of multigravidas. In order to confirm or refute this observation, I describe here a similar analysis of an apparently similar group of subjects.

\section{MATERIALS AND METHODS}

The data analysed were derived from a family study of 132 healthy parous women who had just completed a normal pregnancy. The patients were selected without bias other

Correspondence to: D.C. Kilpatrick, Department of Transfusion Medicine, 2 Forrest Road, Edinburgh EH1 2QN, UK. Tel: 031-255-9398. Fax: 031-255-9469. 
than willingness to provide blood samples. Details, including criteria for selection and the methods used, have been previously reported (Jazwinska et al., 1987). In brief, the subjects were mothers (mean age 29 years) of normal babies following normal pregnancies. A normal baby was defined as born more than 36 weeks after the estimated date of conception, weighing $>2.5 \mathrm{~kg}$, lacking congenital defects and appearing healthy during the perinatal period. A pregnancy was considered normal if singleton, normo-tensive, and free of maternal proteinuria, glycosuria, anaemia and Rhesus alloantibodies. These criteria.for normality are widely accepted and were used to promote standardisation and comparability with other pregnancy populations, and to avoid bias due to any possible HLA associations with disease.

\section{RESULTS}

Of the 132 women in the cohort, 51 were primigravidas and were therefore ineligible for this analysis, while the remaining 81 had had at least one previous pregnancy. Of the latter, six had had only elective abortions before their index pregnancies and were therefore ex́cluded; 8 had had only spontaneous abortions previously, while 67 had had 1 to 4 previous live births with or without additional fetal losses.

The frequency of women with a previous fetal loss was $25 \%(5 / 20)$ amongst HLADR homozygous subjects, and 24\% (13/55) amongst HLA-DR heterozygous subjects. Conversely, relating HLA-DR zygosity to the number of previous miscarriages also showed no trend (Table 1).

\section{DISCUSSION}

Clearly these data show no increase in the occurrence of fetal losses with maternal homozygosity for HLA-DR antigens. This finding is not consistent with the observation of Hoff et al. (1992) and it is hard to reconcile our opposing data. Hoff et al.'s subjects were $58 \%$ black whereas in this study all were white, but Hoff et al. specifically reported an absence of racial differences in their investigation. There were no other identifiable differences (apart from nationality and geographical location) between the two subject populations, and the numbers were comparable.

In selecting the patients described here care was taken to ensure compliance with widely accepted criteria of normality. This was important to exclude bias arising from any HLA disease associations. Such patient information was not provided by Hoff and coworkers, however, so it is possible their cohort could be biased in some unknown way. If HLA-DR homozygosity be relevant as a marker for lethal recessive genes, as opposed to indicating increased feto-maternal compatibility per se, it is possible a relationship might be missed by excluding abnormal pregnancies and births. However, a cohort the size of that described by Hoff and colleagues would have to have a strong bias towards abnormality for that consideration to account for the discrepancy in our results.

If maternal HLA-DR homozygosity be positively associated with fetal wastage, logically this relationship should be manifested most strongly in recurrent aborters. Yet, we found the same (26\%) incidence of HLA-DR homozygosity in a series of 108 recurrent aborters as in this group of 132 controls (Kilpatrick and Liston, 1994), including an incidence of 21 out of $80(26 \%)$ primary aborters. Similar negative results have been reported in other large series of recurrent aborters (Johnson et al., 1988; Eroglu et al. 
Table 1. HLA-DR zygosity in parous women according to the number of previous miscarriages.

No previous miscarriages

DR homozygous : DR heterozygous (\% homozygous)

\begin{tabular}{cc}
\hline 0 & $15: 42(26)$ \\
1 & $4: 11(27)$ \\
2 & $1: 2(33)$ \\
\hline
\end{tabular}

1992). Therefore, the conclusions of Hoff et al. (1992) must be considered doubtful at present.

\section{REFERENCES}

Eroglu, G., Betz, G., Torregano, C. (1992). Impact of histocompatibility antigens on pregnancy outcome. Am. J. Obstet. Gynecol., 166, 1364-1369.

Hoff, C., Trimm, R.F., Thompson, L.W., Peevy, K.J., Fancher, K.M. (1992). A cohort study of maternal HLA-DR homozygosity and increased risk for fetal loss. Am. J. Reprod. Immunol., 28, $17-18$.

Jazwinska, E.C., Kilpatrick, D.C., Smart, G.E., Liston, W.A. (1987). Feto-maternal HLA compatibility does not have a major influence on human pregnancy except for lymphocytotoxin production. Clin. Exp. Immunol., 69, 116-122.

Johnson, P.M., Ramsden, G.H. (1988). Recurrent miscarriage. Bailliere's Clin. Immunol. Allergy, 2, 607-624.

Johnson, P.M., Chia, K.V., Risk, J.M., Barnes, R.M.R., Woodrow. J.C. (1988). Immunological and immunogenetic investigation of spontaneous abortion. Dis. Markers. 6. 163-171.

Kilpatrick, D.C., Liston, W.A. (1993). Influence of histocompatibility antigens in recurrent spontaneous abortion and its relevance to leukocyte immunotherapy. Hum. Reprod., 8, 16541659.

MacQueen, J.M. and Sanfilippo, F.P. (1984). The effect of parental HLA compatibility on the expression of parental haplotypes in offspring. Hum. Immunol.. 11. 155-161.

Morgan, K., Holmes, T.M., Pazderka, F., Dossetor, J.B. (1986). Segregation of HLA A, B haplotypes and the distribution of antigen mismatches between mother and offspring in Hutterite families. Am. J. Hum. Genet., 38, 971-977.

Ober, C., Elias, S., Kostju, D.D., Hauck, W.W. (1992). Decreased fecundability in Hutterite couples sharing HLA-DR. Am. J. Hum. Genet., 50. 6-14. 


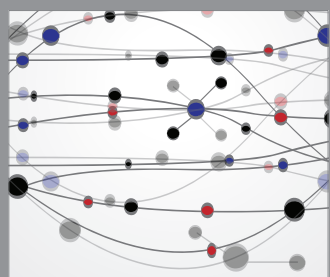

The Scientific World Journal
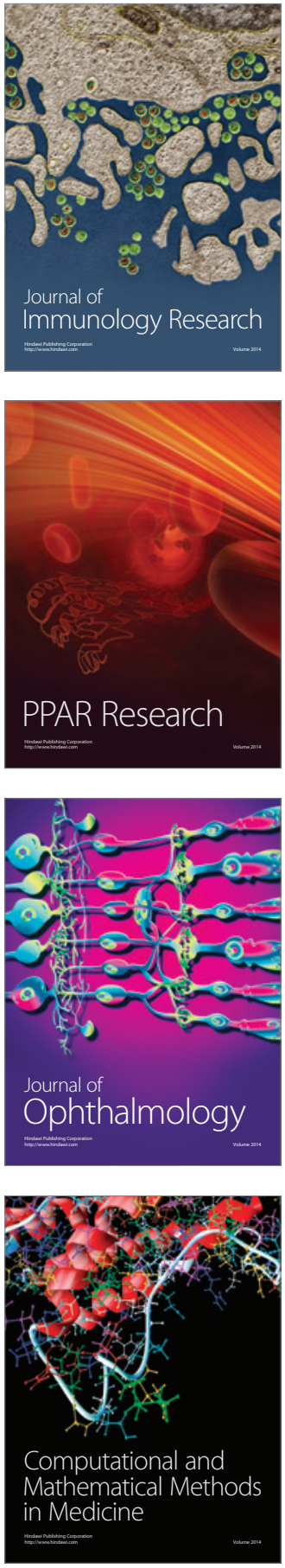

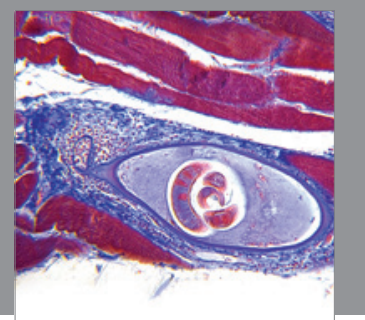

Gastroenterology

Research and Practice
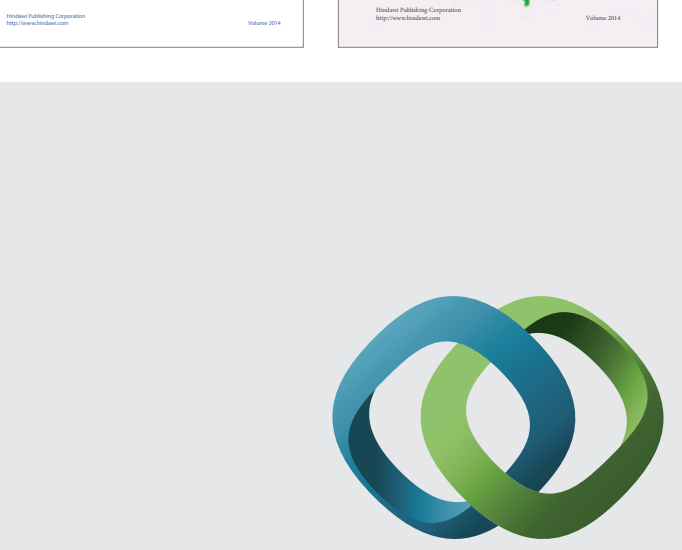

\section{Hindawi}

Submit your manuscripts at

http://www.hindawi.com
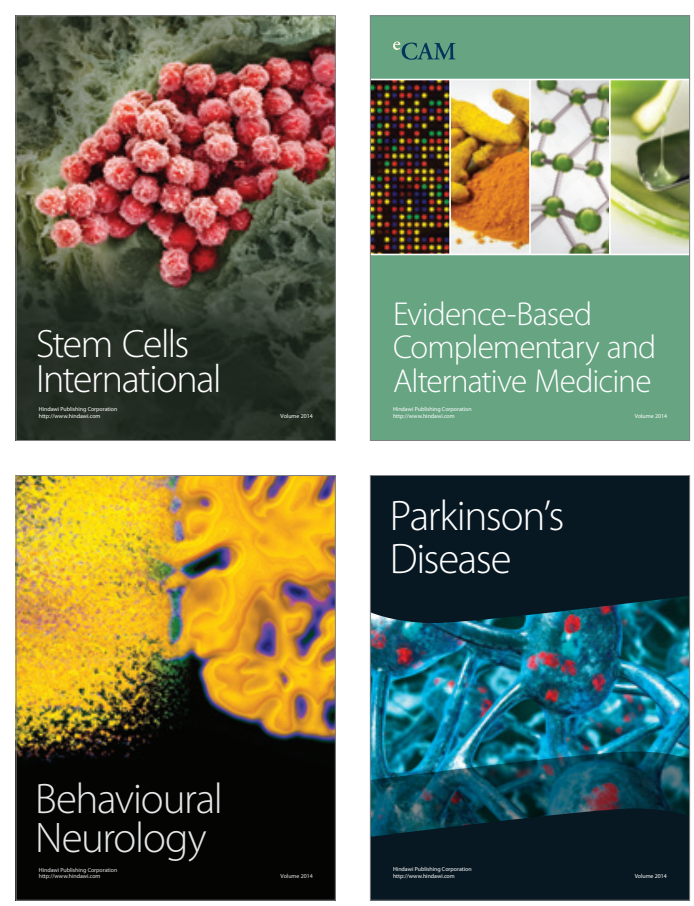

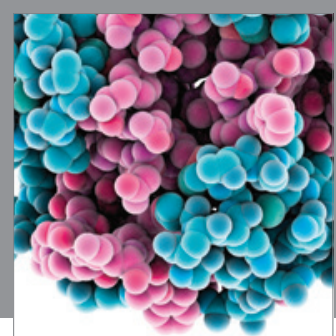

Journal of
Diabetes Research

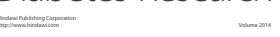

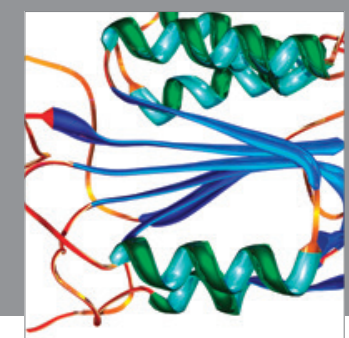

Disease Markers
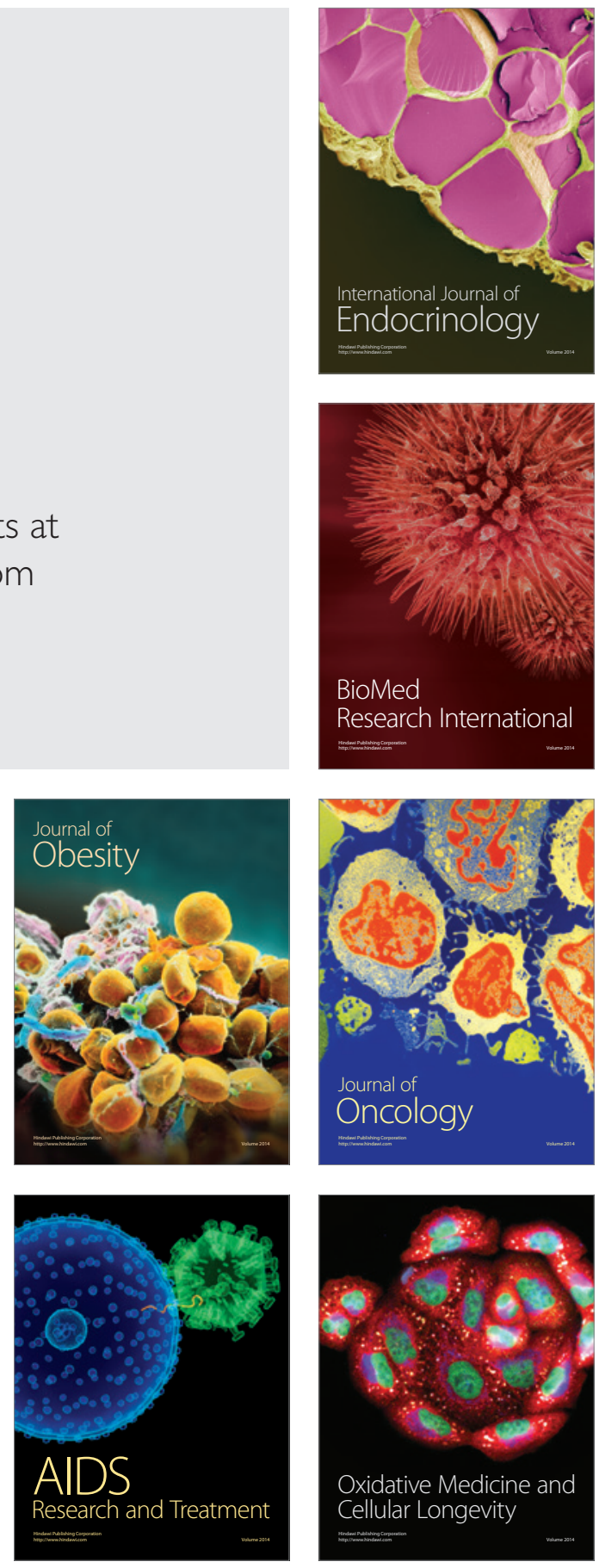